IP Periodica Polytechnica Civil Engineering

59(1), pp. 15, 25. 2015 DOI: $10.3311 / P P c i .7575$

Creative Commons Attribution (1)

RESEARCH ARTICLE

\section{Numerical Study on Shear Stress Variation of RC Wall with L Shaped Section}

\author{
Ali Ahmed Chaouch, Ramdane Boutemeur, Hakim Bechtoula, Abderrahim Bali
}

Received 18-06-2014, revised 03-09-2014, accepted 27-11-2014

\begin{abstract}
In recent years, and after the 2003 Boumerdes earthquake, a new type of building is being constructed in Algeria. The new concept is based on the concentration of reinforced concrete shear walls with L shape at the building corners. The seismic behavior of such configuration is not well known nowadays. Numerical investigation was carried out on reinforced concrete structure to evaluate the stress distribution at the base of the corner L shaped walls. Influence of number of stories, length of the shear wall as well as the thickness of the wall was considered in our investigation. In total, more than 200 numerical models were crated and analyzed. The analyses showed that, reinforced concrete wall with $15 \mathrm{~cm}$, or less, in thickness should have a minimum length of 10 times the thickness; however, for $R C$ walls with a thickness of more than $20 \mathrm{~cm}$, the length of the wall should be greater than 7 times the thickness. In this paper the main results of this investigation are presented.
\end{abstract}

\section{Keywords}

Reinforced concrete $\cdot$ L-shaped shear wall $\cdot$ high-rise $R C$ building $\cdot$ shear behavior $\cdot$ stress distribution

\section{Ali Ahmed Chaouch}

Faculty of Civil Engineering, University of Science and Technology, Houari Boumediene, BP 32 El Alia 16111 Bab Ezzouar, Algiers, Algeria

e-mail: ahmedchali@gmail.com

\section{Ramdane Boutemeur}

Department of Civil Engineering, Polytechnic national school (ENP-URIE), Avenue des Frères Ouddak, Hacen Badi,B.P.182, EL-HARRACH, 16200, Algiers, Algeria

e-mail: boutemeur@hotmail.com

\section{Hakim Bechtoula}

National Earthquake Engineering Research Center (CGS), CGS, 01, Rue Kaddour Rahim, BP 252, Hussein Dey, Alger, Algiers-Algeria

e-mail: bechhakim@gmail.com

\section{Abderrahim Bali}

Department of Civil Engineering, Polytechnic national school (ENP-URIE), Avenue des Frères Ouddak, Hacen Badi,B.P.182, EL-HARRACH, 16200, Algiers,, Algeria

e-mail: balianl@yahoo.fr

\section{Introduction}

After the 2003 earthquake that shook the region of Boumerdes located at $60 \mathrm{~km}$ east from the capital Algiers with a magnitude of 6.8 , a new type of buildings is being erected. Introduction of reinforced concrete, $\mathrm{RC}$, walls at the four corners of the building having an $\mathrm{L}$ shaped is the new configuration that is often used in practice [1]. Reinforced concrete structures with L shape walls offer advantages of open space and flexible architecture modelling. However, until now, seismic behavior of buildings with such configuration is not well known [2-5].

Several high rise buildings in the world are made of reinforced concrete shear walls. This type of structures performed very well during the past earthquakes better than reinforced concrete frame buildings.

Concrete wall structures are well known for their excellent performance during earthquakes. Since 1963, no concrete building with shear walls has collapsed during an earthquake [19]. In some cases, buildings with concrete structural walls showed little or no damage when neighbouring reinforced concrete frame buildings were severely damaged or destroyed.

One type of seismic force resisting structure used in high-rise wall buildings is a centrally located core without supplemental moment resisting frames.

Effect of some parameters on the behavior and performance of reinforced concrete shear walls was carried out in the past. However, these studies were conducted on rectangular reinforced concrete shear walls. Frequently, designers are using other configurations beside the rectangular cross sections, such as T-shaped, $\mathrm{H}$ shaped and $\mathrm{U}$ shaped cross sections, in order to reach higher levels of strength and stiffness.

In many cases, these complex members show completely different behaviors than rectangular walls, and particular consideration is needed when these shapes are used in structures. Among all types of flanged shear walls, the ones with T-, H-, and U-shaped cross sections have been those most studied by researchers [6-21]. Research has been more focused on walls with symmetric cross sections, and few studies in the literature report the behavior of flanged shear walls with asymmetric cross sections, such as L-shaped walls. The stiffness, strength, and 
ductility of such walls can be completely different in opposite directions [12], and these walls even sometimes exhibit different failure modes in opposite directions.

Inada et al. (2008) [22] studied the effect of loading direction and the section configuration on the seismic behavior of $\mathrm{RC}$ shear walls. Three reinforced concrete specimens of an Lshaped core-wall was constructed with $1 / 4.5$ scale and statically loaded to study the effect of loading direction and the section configuration on the seismic performance of the core-wall. Two of the specimens were the equilateral L-shaped walls, and the third one was the inequilaterally L-shaped wall. All specimens showed large deformation capability until the peak load. The peak load was reached at drift angle around $1.0 \%$ in positive direction when experiencing a vertical load about $30 \%$ of the axial load capacity. The failure was caused by the crushing of concrete at the compression zone. The failed region in equilateral one type of L-shaped wall and inequilaterally L-shaped wall covered a relatively larger area than predicted by a section analysis and that for the second equilateral L-shaped wall covered the whole flange section. It would be better to provide higher confinement to the larger region of concrete to secure high ductility. The peak load was not reached in the negative direction since the axial load was low. A simple fiber model simulated well the lateral load-drift angle relation if the moment - curvature relation at the wall base region was properly modelled by considering pull-out of longitudinal reinforcement and local crushing of concrete.

A testing program was carried out by Karamlou et al. (2012) [23] on four slender shear walls with L-shaped cross sections under the combined action of constant axial and cyclic lateral loads. The specimens were built with industrialized R-ICF panels in which vertical reinforcements were provided in the panels at the time of fabrication. In addition, these vertical bars were attached together using some spot welded crossties. This research was conducted to assess behavioral aspects of an Lshaped shear wall constructed with this system. Two levels of confinement were applied to the specimens by using additional confining hoops and the panel's spot welded crossties. All the specimens exhibited a flexural mode of failure characterized by a crushing of the boundary elements. However, the occurrence of the web crushing phenomenon was shown to decrease the stiffness, strength and ductility and increase the rotation of the walls. Higher flexural strength of the walls in one direction against the other and the application of large inelastic lateral loads were important factors in increasing the possibility of web crushing.

This paper presents the main results of a numerical study on shear stress variation of $\mathrm{RC}$ wall with $\mathrm{L}$ shaped section. The aim of the research was to evaluate the influence of some parameters such as thickness/length of the shear wall and number of stories on the shear stress variation.

\section{Considered building}

To carry out our numerical analysis, we have considered a regular RC building in plan with $\mathrm{L}$ shaped section shear walls at the four corners as illustrated in Fig. 1. The building has an equal story height of 3.00 meters. The three considered parameter in our analysis are:

$t \quad$ Thickness of the RC walls,

$l \quad$ Length of the walls,

$N \quad$ Number of stories.

In the actual Algerian seismic regulation RPA99/V2003 (2003), reinforced concrete shear wall is defined as an element whose length is at least 4 times the thickness. Three wall thicknesses were considered in our study: $15 \mathrm{~cm}, 20 \mathrm{~cm}$ and $25 \mathrm{~cm}$. The ratio length to thickness $(l / t)$ varied from 4 to 21 for a thickness of $15 \mathrm{~cm}$, from 4 to 16 for a thickness of $20 \mathrm{~cm}$ and from 4 to 13 for a thickness of $25 \mathrm{~cm}$.

As for buildings, we considered five buildings with 4, 6, 11, 16 and 21 stories which represent the common buildings that are used in Algeria. Taking into account the variation of the three parameters two hundred (200) models were analyzed. Fig. 1(b), (c) and (d) show some models of the analyzed buildings.

All buildings were designed according the Algerian seismic regulation RPA99/V2003 (RPA, 2003). We supposed that the building is erected on S2 soil type. Structures were modeled in a 3D space using the nonlinear Robot software [24] as illustrated in Fig. 1 .

The total design seismic base shear force is estimated using the static equivalent force procedure (e. g., C.G.S, 2003), and evaluated as:

$$
V=\frac{A D Q}{R} W
$$

Where:

$V \quad$ Total design base shear force,

A Design base acceleration coefficient,

$D$ Mean dynamic amplification factor, function of the fundamental natural period,

$Q \quad$ Quality factor,

$R \quad$ Behavior factor of the structure,

$T \quad$ Natural fundamental period of the structure,

W Total seismic weight.

The total seismic force is distributed over the height of the structure as follows:

$$
F_{k}=\frac{\left(V-F_{t}\right) W_{k} h_{k}}{\sum_{i=1}^{N} W_{i} h_{i}}
$$

Where:

$F_{k} \quad$ Seismic horizontal force at the $k^{\text {th }}$ level.

$F_{t} \quad$ Shall be assumed to be concentrated at the top of the structure in addition to $F_{n}$, and equal to $0.07 \mathrm{TV}$, with the 


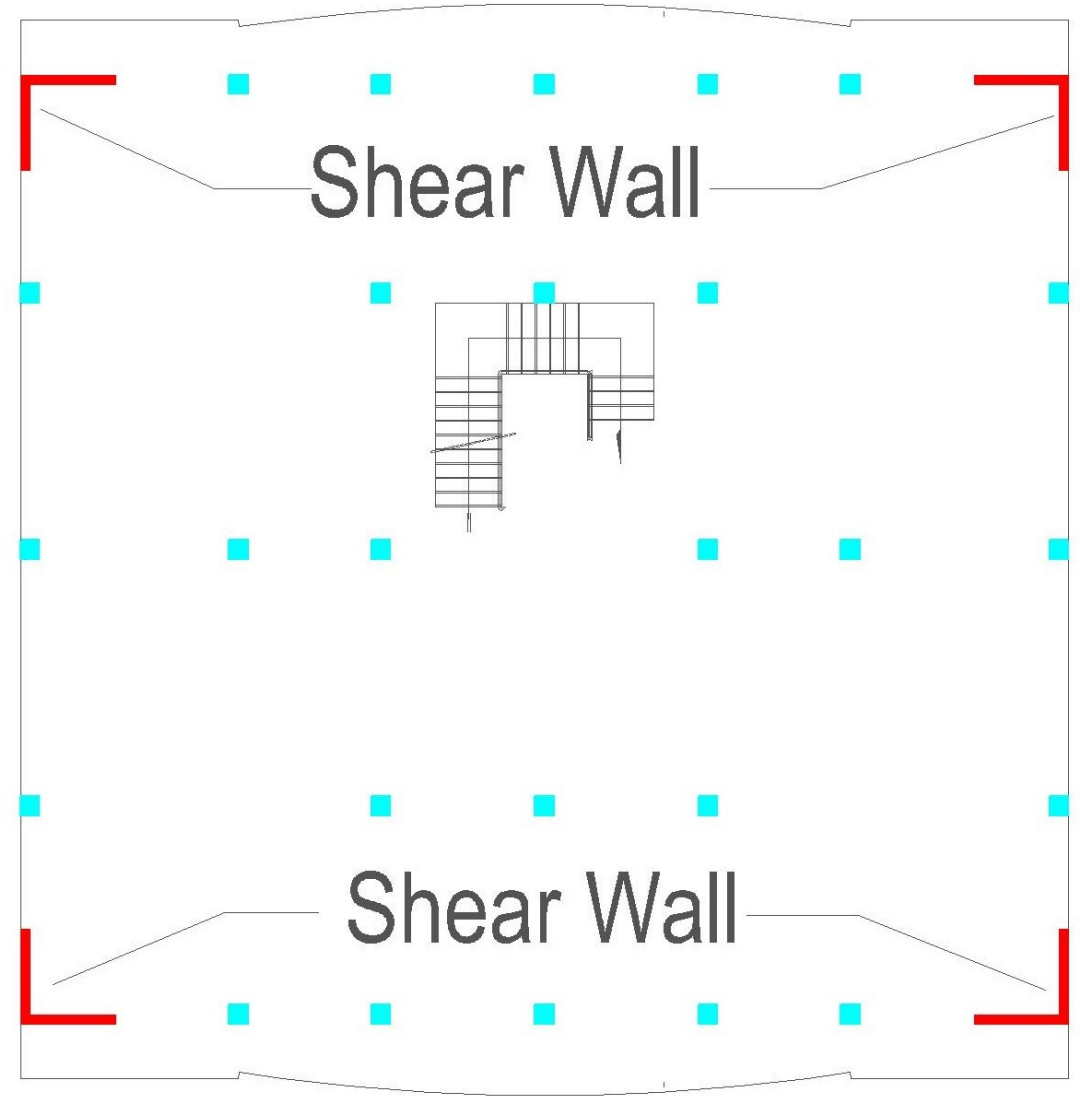

(a) Plan view

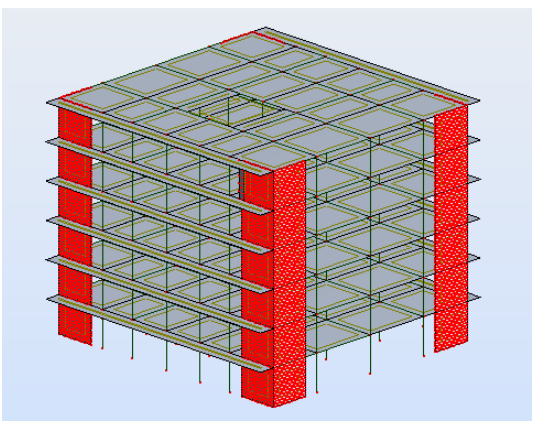

(b) Six stories

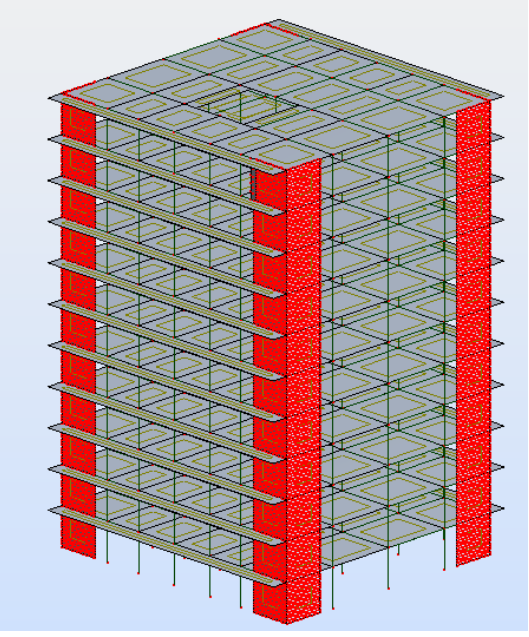

(c) Eleven Stories

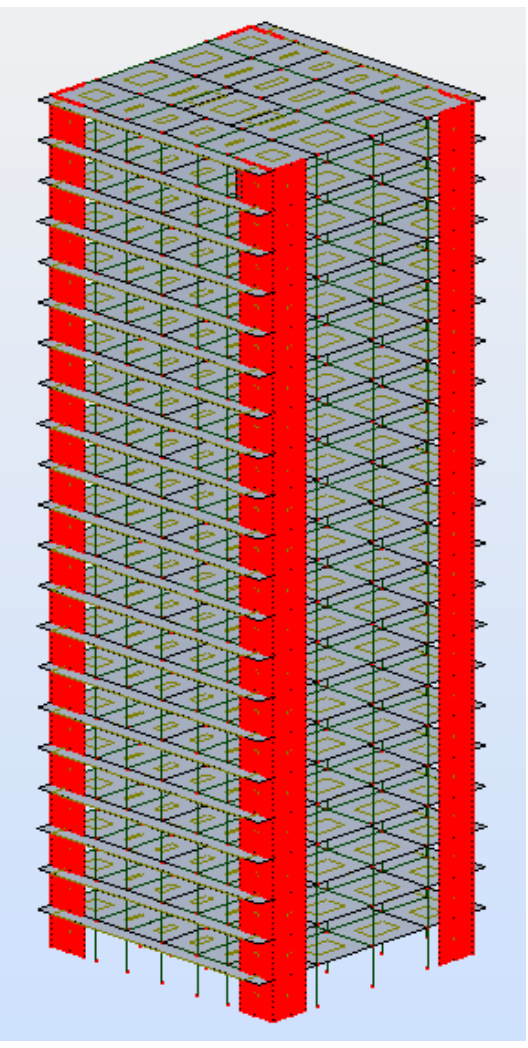

(d) Twenty one stories

Fig. 1. Configuration and models of the 6,11 and 21 story buildings 
condition that $F_{t} \leq 0.25 \mathrm{~V}$ and $F_{t}=0$ when the period does not exceed $0.7 \mathrm{sec}$.

$W_{k} \quad$ Seismic weight at the $k^{\text {th }}$ level.

$h_{k} \quad$ Height from the base to the $k^{\text {th }}$ level.

The mean dynamic amplification factor, $D$, function of the fundamental natural period is given by the following equation:

$$
\mathbf{D}=\left[\begin{array}{ccc}
2.5 \eta & \text { if } & 0 \leq T \leq T_{2} \\
2.5 \eta\left(\frac{T_{2}}{T}\right)^{2 / 3} & \text { if } & T_{2} \leq T \leq 3.0 \mathrm{sec} \\
\frac{2.5 \eta\left(\frac{T_{2}}{3.0}\right)^{2}}{3}\left(\frac{3.0}{T}\right)^{5 / 3} & \text { if } & T \geq 3.0 \mathrm{sec}
\end{array}\right.
$$

Where:

$T_{2} \quad$ is the characteristic period, associated with the site category and shown in Table 1

$\eta$

is the modified damping factor given by:

$$
\eta=\sqrt{\frac{7}{2+\xi}} \geq 0.7
$$

Where:

is the percentage of the critical damping, which is a function of the material type.

Tab. 1. Values of $T_{2}$

\begin{tabular}{ccccc}
\hline Soil type & $\mathrm{S} 1$ & $\mathrm{~S} 2$ & $\mathrm{~S} 3$ & $\mathrm{~S} 4$ \\
$T_{2}(\mathrm{sec})$ & 0.30 & 0.40 & 0.50 & 0.70
\end{tabular}

\section{Analysis results}

From hereafter, the discussed results and the comparisons are those related to the corner location, intersection between the two RC walls as illustrated in Fig. 2, as an example. This zone is the area where the shear stress is the most important, stress concentration. This remark was observed for all models analyzed by the authors and also confirmed experimentally by Inada et al [22].

The obtained maximum shear stresses for the different analyzed models are summarized in Table 2 Fig. 3 shows the shear stress distribution versus the $(l / t)$ ratio, for the dead load, life load and earthquake combination. It is clearly shown that for buildings with 21,16 and 11 stories the shear stress increased until reaching a peak stress and after that decreased undependably of the walls thickness. However, for buildings with 4 and 6 stories, peak stress was observed only for walls having a thickness of 15 and $20 \mathrm{~cm}$; for the other thickness, shear stress varied nearly linearly with respect to the $(l / t)$ ratio as shown in Fig. 3(c). For some building heights and wall thicknesses, increasing the length of the shear walls (1) can increase the value of the shear stress as seen in Fig. 3 (a) and (b). As an example, for buildings with walls of $15 \mathrm{~cm}$ the shear stress increases from $l / t=4$ to $l / t=10$. These values are respectively 4 and 7 for buildings with walls of $20 \mathrm{~cm}$. It is suggested for RC shear walls of $15 \mathrm{~cm}$ thickness to have a length greater than 10 times the thickness, $1>10 \mathrm{t}$. For walls with 20 and $25 \mathrm{~cm}$ thickness this value is 7 and 5, respectively, as illustrated in Fig. 3(d).

Fig. 4 shows the shear stress variation for a given building with different wall thicknesses. It can be clearly observed that, when the thickness of the walls increases the value of the peak stress shift toward lower values of the ratio $(t / l)$. The values of the maximum shear stress, that took place at different $l / t$ ratios, were the same for buildings of 4 and 6 stories regardless the thickness of the walls, as illustrated in Fig. 4 a) and (b). For tall buildings, however, a difference in shear stress was observed especially for buildings having 16 and 21 stories. This means that for tall buildings, thickness of the walls is an important parameter as for the maximum stress value and stress distribution.

Effect of wall thickness on shear stress variation is shown in Fig. 5 for the selected buildings. For 4 and 6 story buildings, the shear stress of building having $25 \mathrm{~cm}$ thick walls is lower than that for buildings with 15 and $20 \mathrm{~cm}$ thick walls. While the height of the building increases (11, 16 and 21 stories), the shear stress of buildings with $25 \mathrm{~cm}$ thick walls became higher than that observed for the two other thicknesses.

Fig. 6 shows the variation of the shear force ratio carried by the reinforced concrete walls, $\mathrm{Vw}$, to the total input earthquake force, $\mathrm{Vt}$, for all buildings and the 3 different thicknesses. It is well shown that the slope of the curves is much higher for small $(l / t)$ ratios than for large ratios. Besides that, the amount of enhancement of the $(\mathrm{Vw} / \mathrm{Vt})$ ratio is important while passing from a wall thickness of 15 to $25 \mathrm{~cm}$ than a wall thickness of 15 to $20 \mathrm{~cm}$, especially for small $(l / t)$ ratios. As an example Table 2. compares the $(\mathrm{Vw} / \mathrm{Vt})$ for 2 values of $(l / t)$ that are 4 and 12. As shown in the Table 3, for a small ratio of $L / t=4$, the enhancement $(\mathrm{Vw} / \mathrm{Vt})$ ratio passes from 1.59 to 2.61 , while increasing the walls thicknesses from 15 to $20 \mathrm{~cm}$ and from 15 to $25 \mathrm{~cm}$, respectively. These values were only 1.10 and 1.22 for a ratio $l / t$ of 12 .

The investigation showed also that the $(\mathrm{Vw} / \mathrm{Vt})-(l / t)$ relationships is the same for a given walls thickness, regardless the number of stories, $N$, as illustrated in Fig. 7

\section{Conclusions}

Main results of numerical analysis on shear stress variation in an $\mathrm{L}$ shaped reinforced concrete wall were presented. The analysis was carried out for 6 RC building with 4, 611,16 and 21 stories. For each building 3 wall thicknesses were selected that are 15,20 and $25 \mathrm{~cm}$. In total more than 200 models were crated and analyzed. It was shown that the shear stress increased until reaching a peak stress and after that decreased undependably of the walls thickness, except for buildings with 4 and 6 stories and $25 \mathrm{~cm}$ wall thickness where the shear stress varied nearly linearly with respect to the $(l / t)$ ratio. As it was discussed, increasing the length of the shear walls (l) increased the value of the shear stress. Shear stress for buildings with walls of $15 \mathrm{~cm}$ thickness increased from $l / t=4$ to $l / t=10$. These values were 


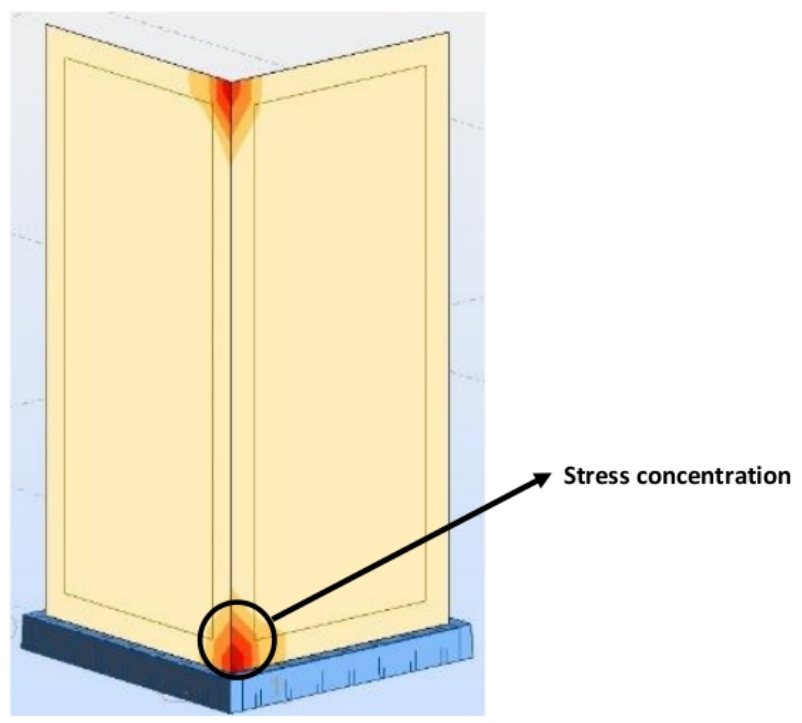

Fig. 2. Location of the stress concentration (comparison point)

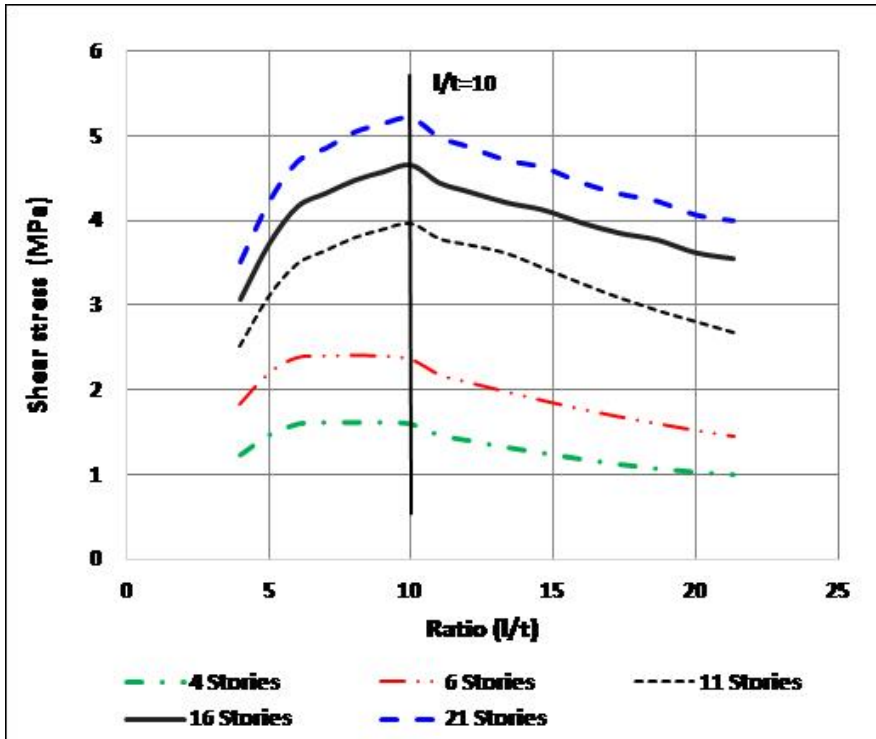

(a) Walls with $t=15 \mathrm{~cm}$

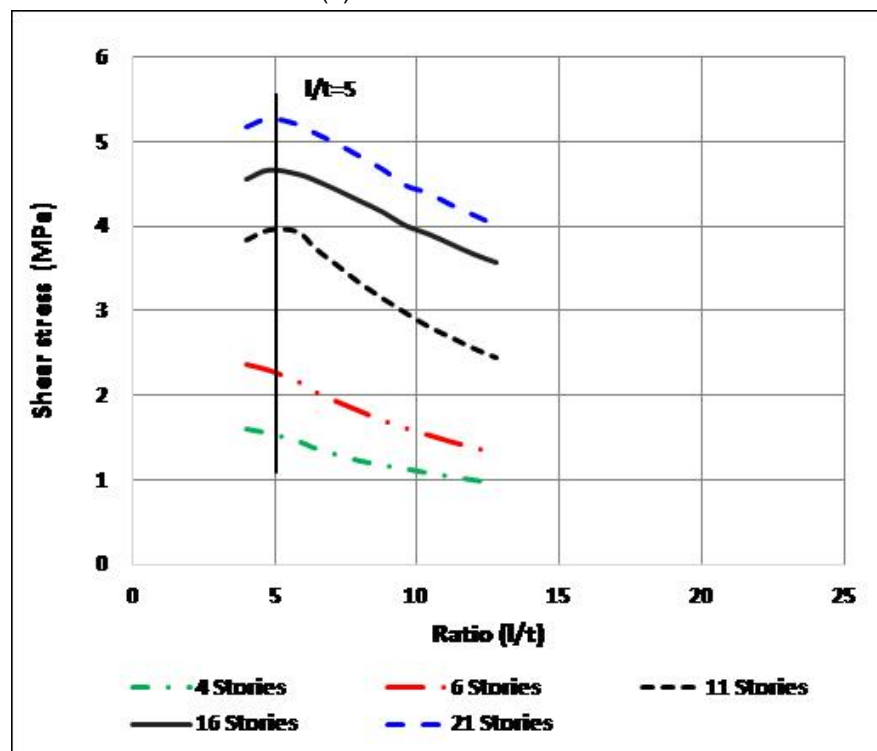

(c) Walls with $t=25 \mathrm{~cm}$

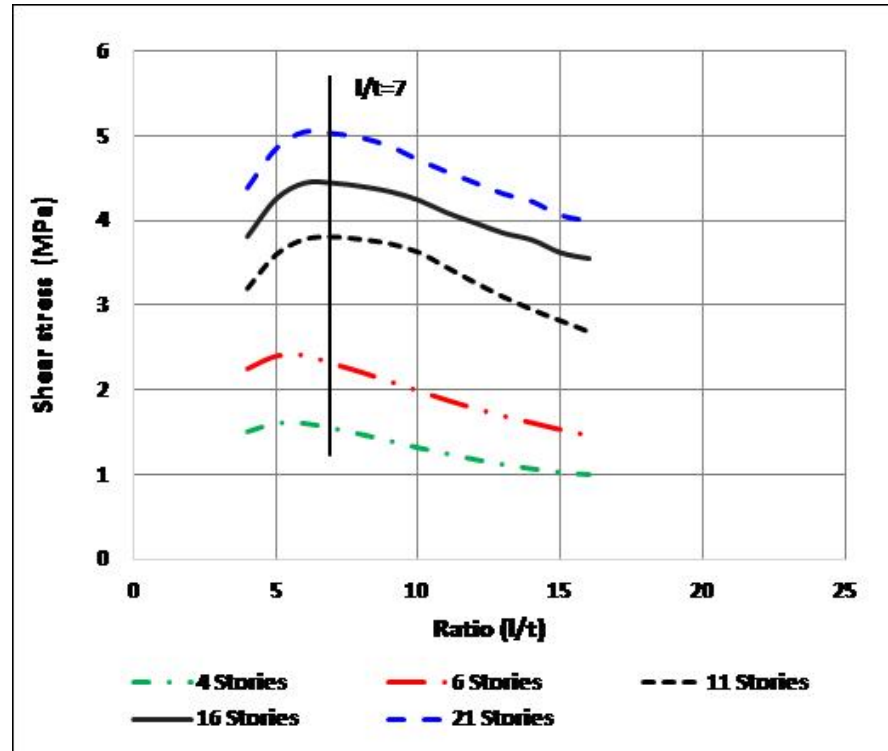

(b) Walls with $t=20 \mathrm{~cm}$

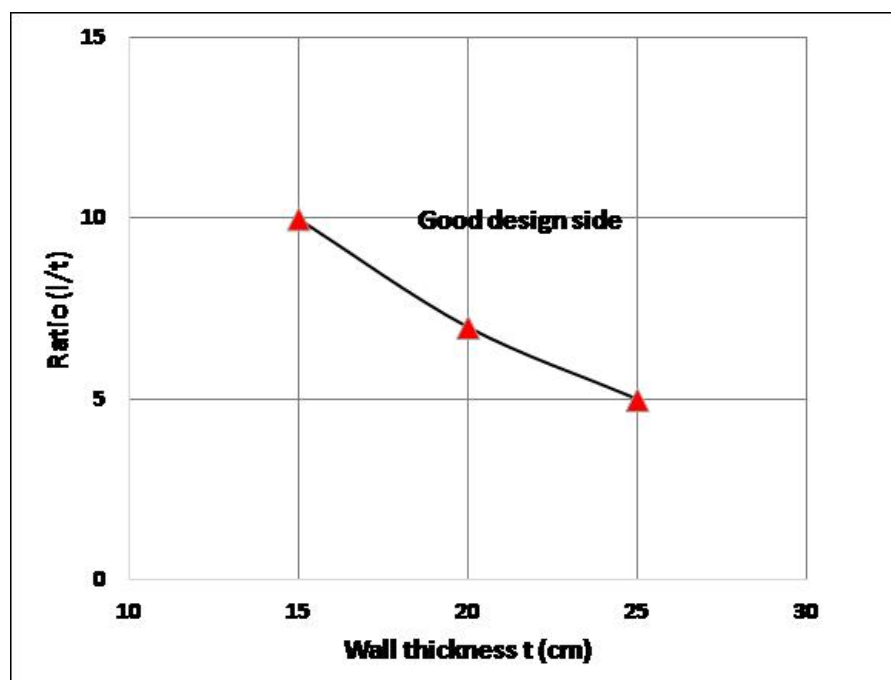

(d) Variation of peak stress with respect to wall thickness

Fig. 3. Shear stress- $(l / t)$ ratio relationships 
Tab. 2. Summary of the shear stress variation with respect to the selected parameters

\begin{tabular}{|c|c|c|c|c|c|c|}
\hline \multirow{2}{*}{$\begin{array}{c}\text { Thickness } \\
t(\mathrm{~cm})\end{array}$} & \multirow[t]{2}{*}{ Ratio $l / t$} & \multicolumn{5}{|c|}{ Shear stress (MPA) } \\
\hline & & $N=4$ & $N=6$ & $N=11$ & $N=16$ & $N=\mathbf{2 1}$ \\
\hline \multirow{16}{*}{15} & 4 & 1,23 & 1.83 & 2,52 & 3,07 & 3,51 \\
\hline & 5 & 1.46 & 2,19 & 3,1 & 3,72 & 4,22 \\
\hline & 6 & 1.59 & 2,38 & 3,49 & 4,16 & 4,7 \\
\hline & 7 & 1.61 & 2,4 & 3,65 & 4,32 & 4,86 \\
\hline & 8 & 1.61 & 2,41 & 3,8 & 4,47 & 5,05 \\
\hline & 9 & 1.61 & 2,4 & 3,9 & 4,57 & 5,15 \\
\hline & 10 & 1.59 & 2,36 & 3,97 & 4,65 & 5,22 \\
\hline & 11 & 1.46 & 2,18 & 3,79 & 4,44 & 4,99 \\
\hline & 12 & 1.40 & 2,09 & 3,72 & 4,34 & 4,88 \\
\hline & 13.3 & 1.32 & 1,98 & 3,62 & 4,21 & 4,72 \\
\hline & 14.6 & 1.25 & 1,87 & 3,44 & 4,12 & 4,63 \\
\hline & 16 & 1.18 & 1,77 & 3,26 & 3,97 & 4,45 \\
\hline & 17.33 & 1.12 & 1,68 & 3,09 & 3,85 & 4,32 \\
\hline & 18.66 & 1.07 & 1,6 & 2,94 & 3,77 & 4,23 \\
\hline & 20 & 1.03 & 1,52 & 2,81 & 3,62 & 4,07 \\
\hline & 21.33 & 1.00 & 1,45 & 2,68 & 3,55 & 4 \\
\hline \multirow{13}{*}{20} & 4 & 1,51 & 2,24 & 3,19 & 3,81 & 4,39 \\
\hline & 5 & 1,61 & 2,39 & 3,59 & 4,25 & 4,85 \\
\hline & 6 & 1,61 & 2,4 & 3,77 & 4,44 & 5,05 \\
\hline & 7 & 1,55 & 2,3 & 3,8 & 4,44 & 5,03 \\
\hline & 8 & 1,48 & 2,2 & 3,77 & 4,4 & 4,98 \\
\hline & 9 & 1,4 & 2,09 & 3,72 & 4,34 & 4,88 \\
\hline & 10 & 1,32 & 1,98 & 3,62 & 4,24 & 4,72 \\
\hline & 11 & 1,25 & 1,87 & 3,44 & 4,09 & 4,58 \\
\hline & 12 & 1,18 & 1,77 & 3,26 & 3,97 & 4,45 \\
\hline & 13 & 1,12 & 1,68 & 3,09 & 3,85 & 4,32 \\
\hline & 14 & 1,07 & 1,6 & 2,94 & 3,77 & 4,23 \\
\hline & 15 & 1,03 & 1,52 & 2,81 & 3,62 & 4,07 \\
\hline & 16 & 1 & 1,45 & 2,68 & 3,55 & 4 \\
\hline \multirow{12}{*}{25} & 4 & 1,59 & 2,36 & 3,84 & 4,56 & 5,18 \\
\hline & 4,8 & 1,54 & 2,29 & 3,96 & 4,67 & 5,28 \\
\hline & 5,8 & 1,45 & 2,16 & 3,94 & 4,62 & 5,21 \\
\hline & 6,4 & 1,37 & 2,04 & 3,75 & 4,55 & 5,11 \\
\hline & 7,2 & 1,29 & 1,92 & 3,54 & 4,43 & 4,98 \\
\hline & 8 & 1,22 & 1,81 & 3,33 & 4,3 & 4,83 \\
\hline & 8,8 & 1,17 & 1,7 & 3,15 & 4,17 & 4,68 \\
\hline & 9,6 & 1,13 & 1,61 & 2,98 & 4,01 & 4,49 \\
\hline & 10,4 & 1,08 & 1,53 & 2,82 & 3,91 & 4,4 \\
\hline & 11,2 & 1,04 & 1,45 & 2,69 & 3,79 & 4,26 \\
\hline & 12 & 1 & 1,38 & 2,56 & 3,67 & 4,14 \\
\hline & 12,8 & 0,96 & 1,32 & 2,45 & 3,57 & 4,02 \\
\hline
\end{tabular}

Tab. 3. Enhancement of $(\mathrm{Vw} / \mathrm{Vt})$ ratios with respect to the $l / t$ ratios

\begin{tabular}{cccccc}
\hline$l / t$ & $t=15$ & $t=20$ & $t=25$ & $t 20 / t 15$ & $t 25 / t 15$ \\
\hline 4 & 24.51 & 38.89 & 63.92 & 1.59 & 2.61 \\
12 & 74.68 & 82.16 & 91.45 & 1.10 & 1.22 \\
\hline
\end{tabular}




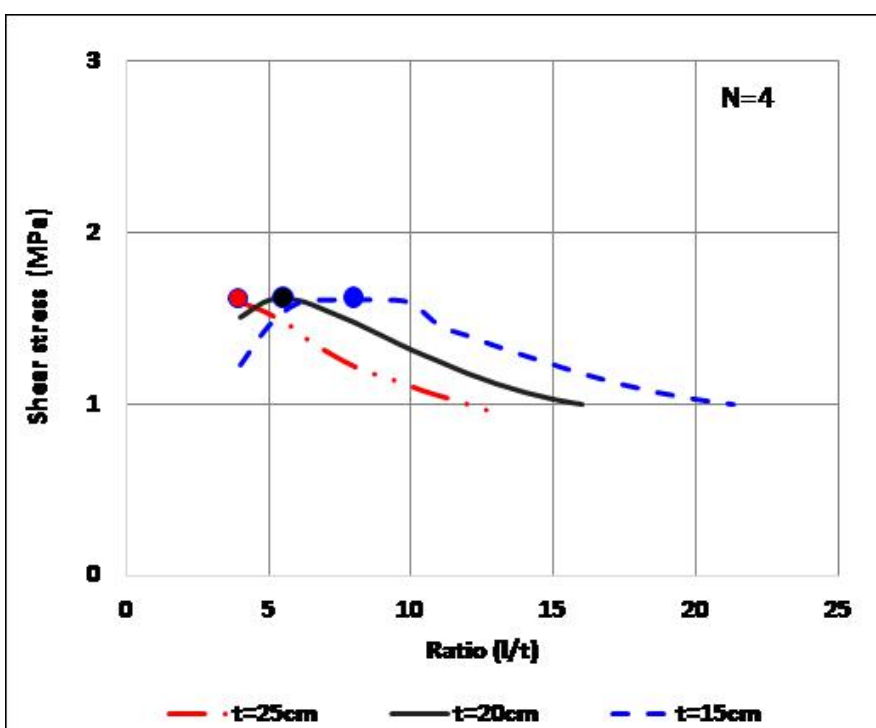

(a) Four story building: $N=4$

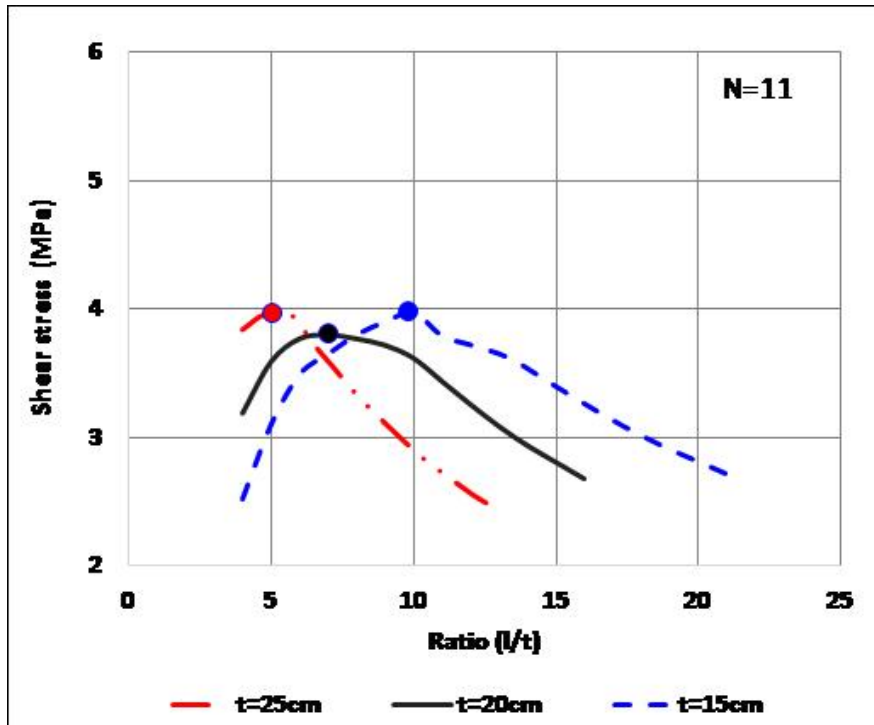

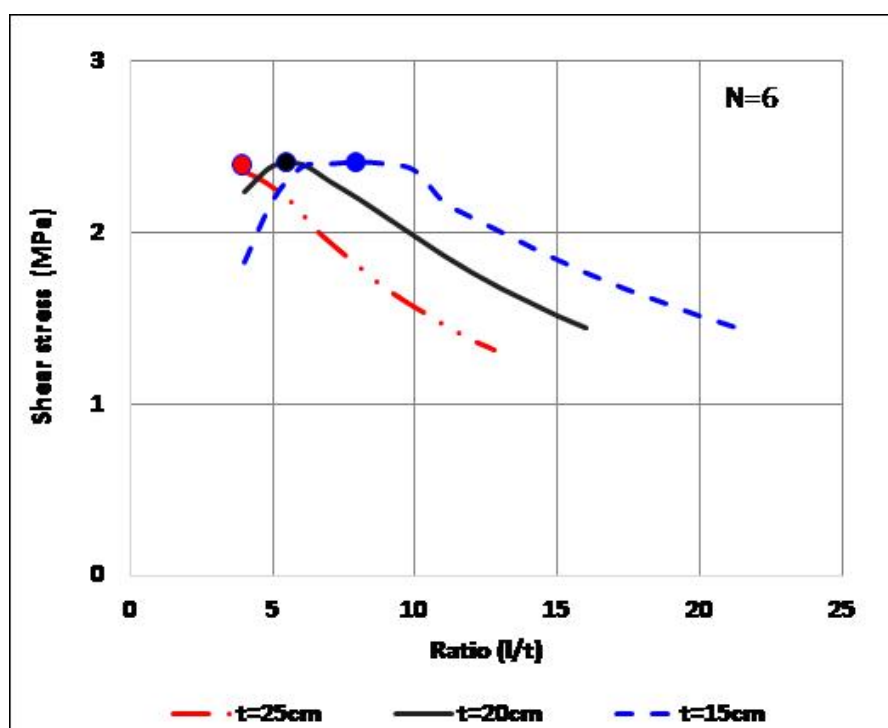

(b) Six story building: $N=6$

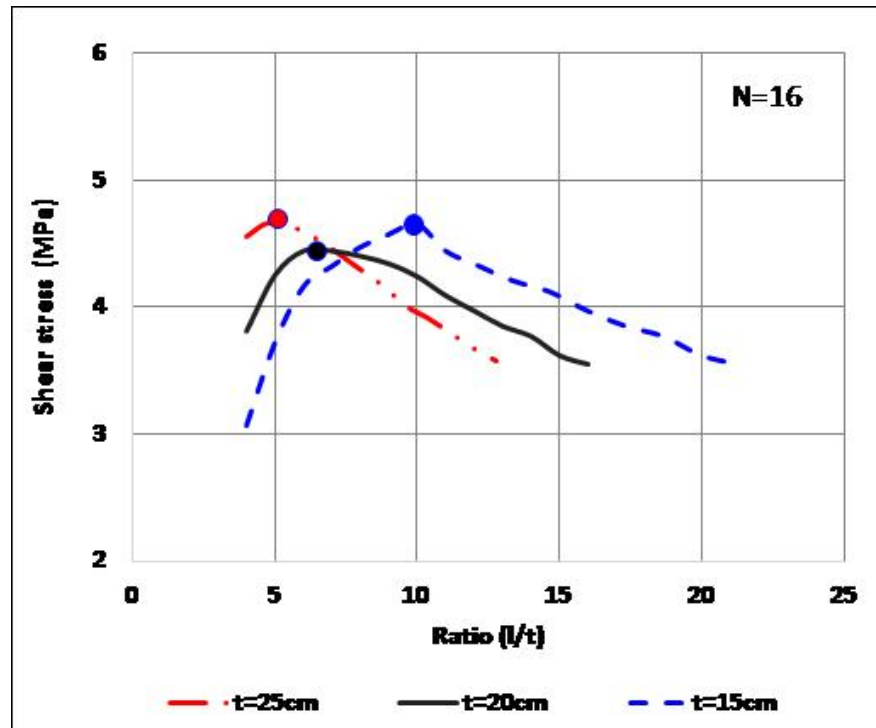

(d) Sixteen story building: $N=16$

(c) Eleven story building: $N=11$

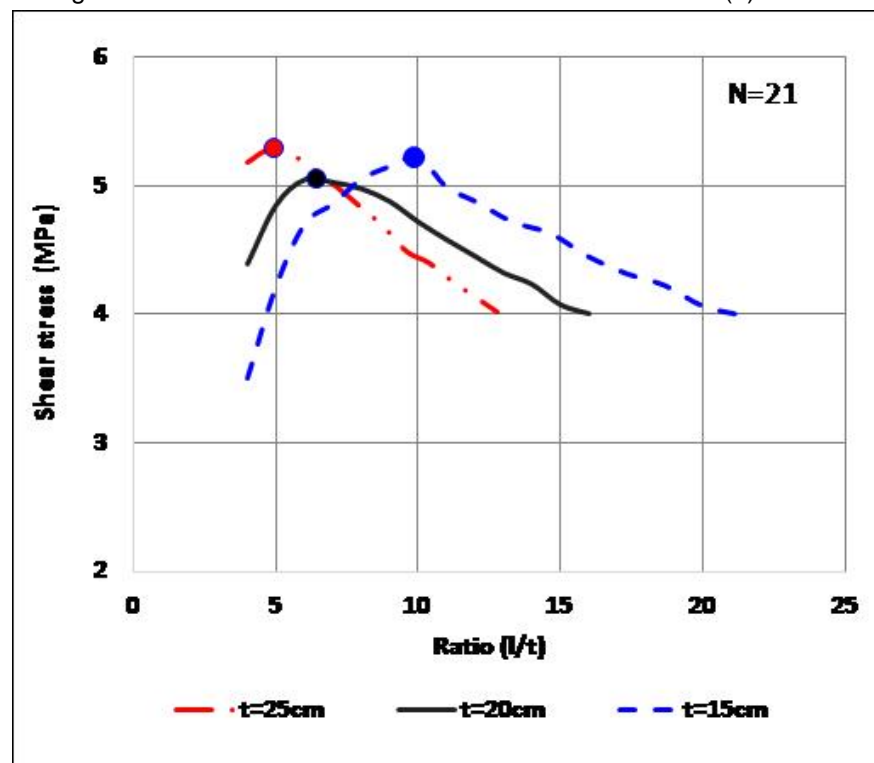

(e) Twenty one story building: $N=21$

Fig. 4. Maximum shear stress distribution for different number of story buildings (N) 


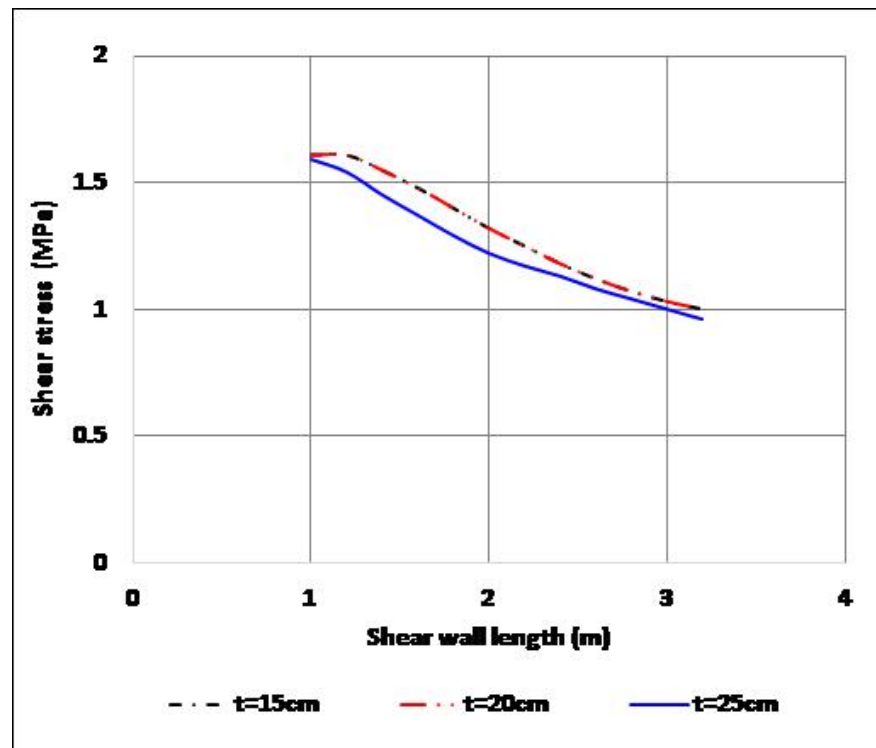

(a) Four story building: $N=4$

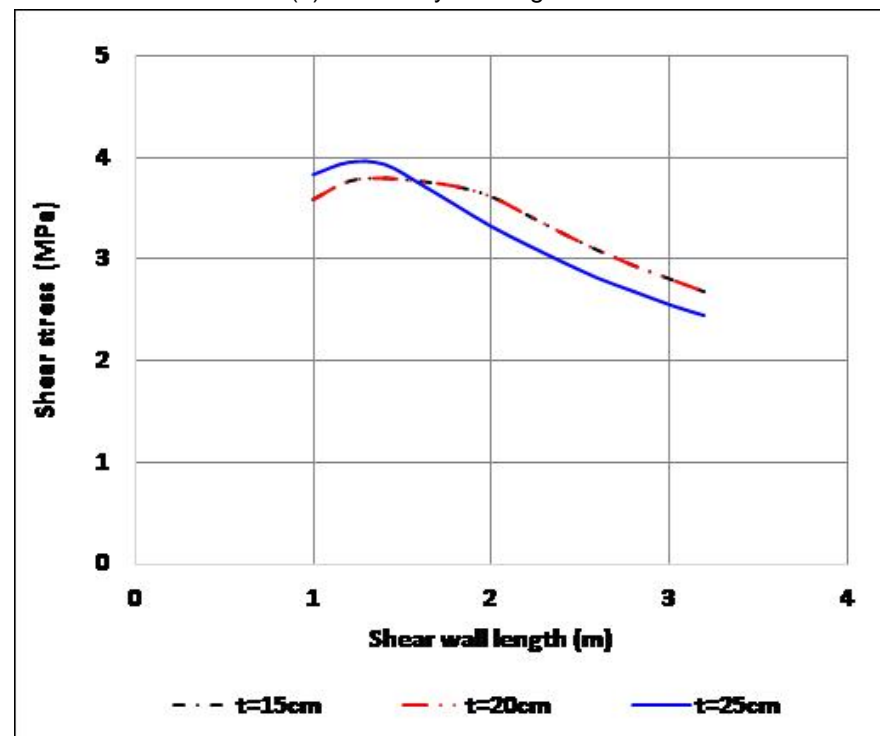

(c) Eleven story building: $N=11$

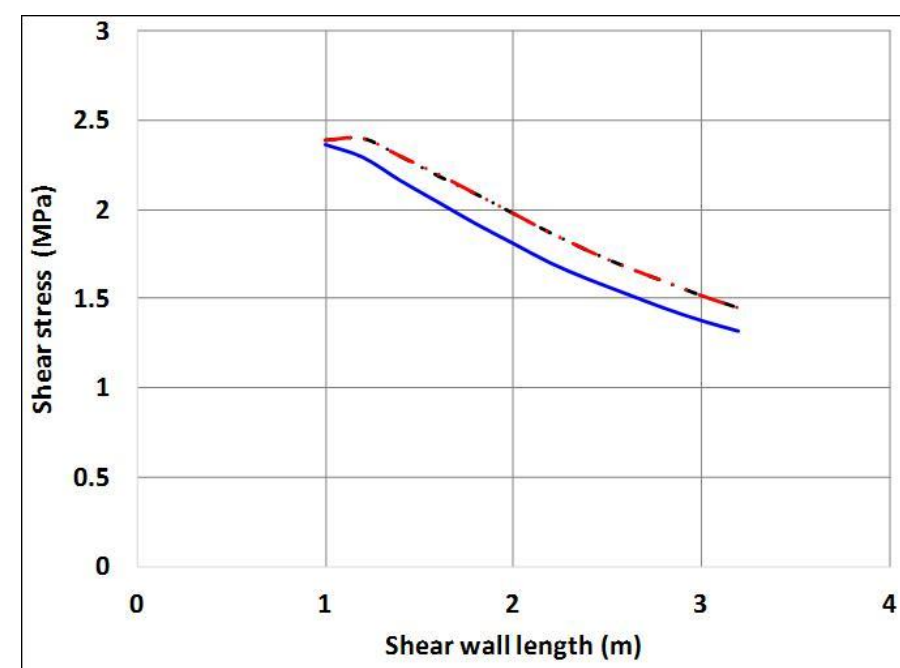

$-\cdots \mathrm{t}=15 \mathrm{~cm} \quad-\cdots \mathrm{t}=20 \mathrm{~cm} \quad-\mathrm{t}=25 \mathrm{~cm}$

(b) Six story building: $N=6$

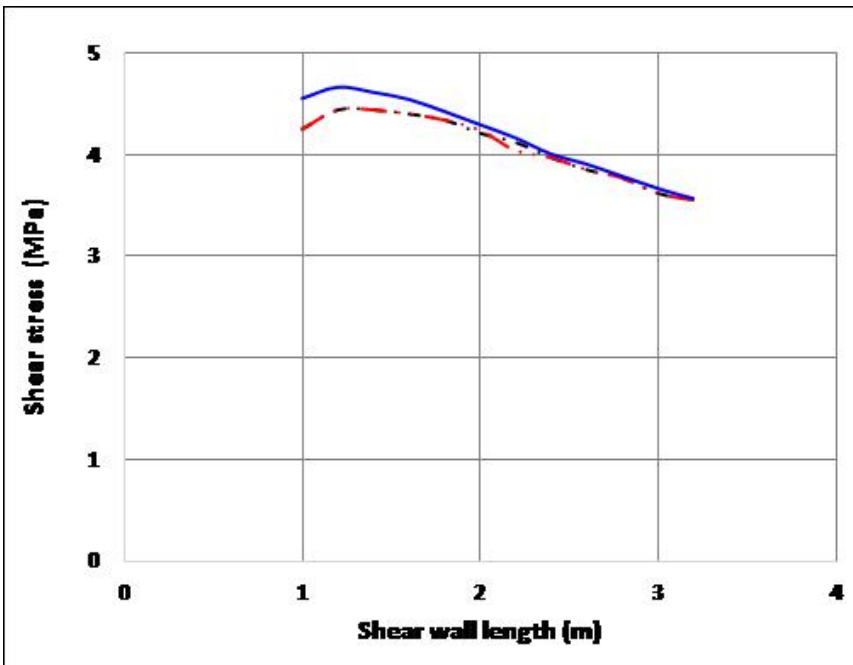

$-\cdot-t=15 \mathrm{~cm} \quad-\cdots t=20 \mathrm{~cm}$

(d) Sixteen story building: $N=16$

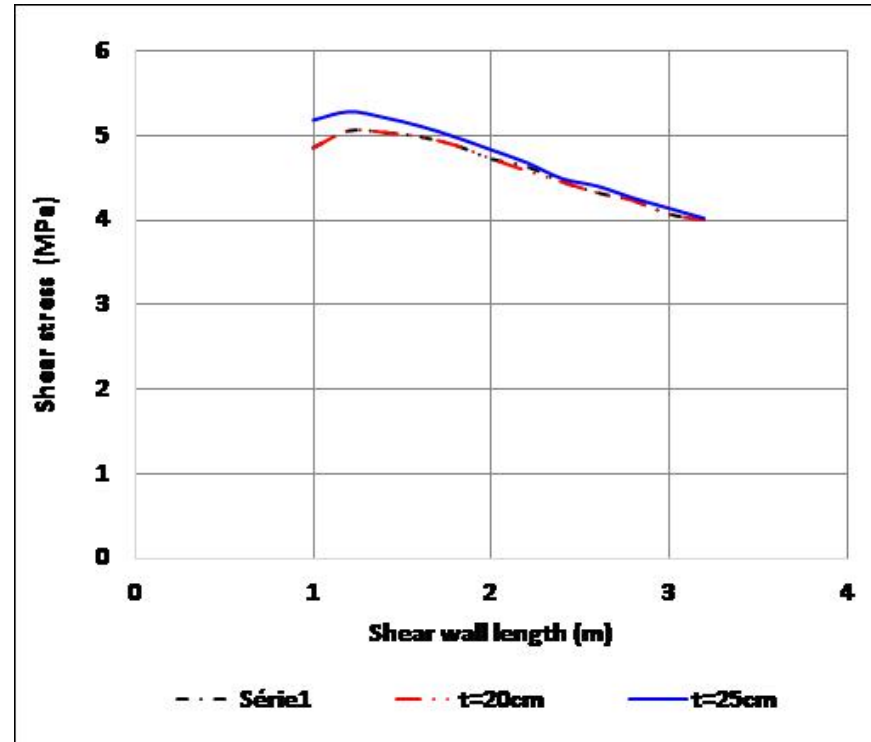

(e) Twenty one story building: $N=21$

Fig. 5. Effect of wall thickness on shear stress distribution 

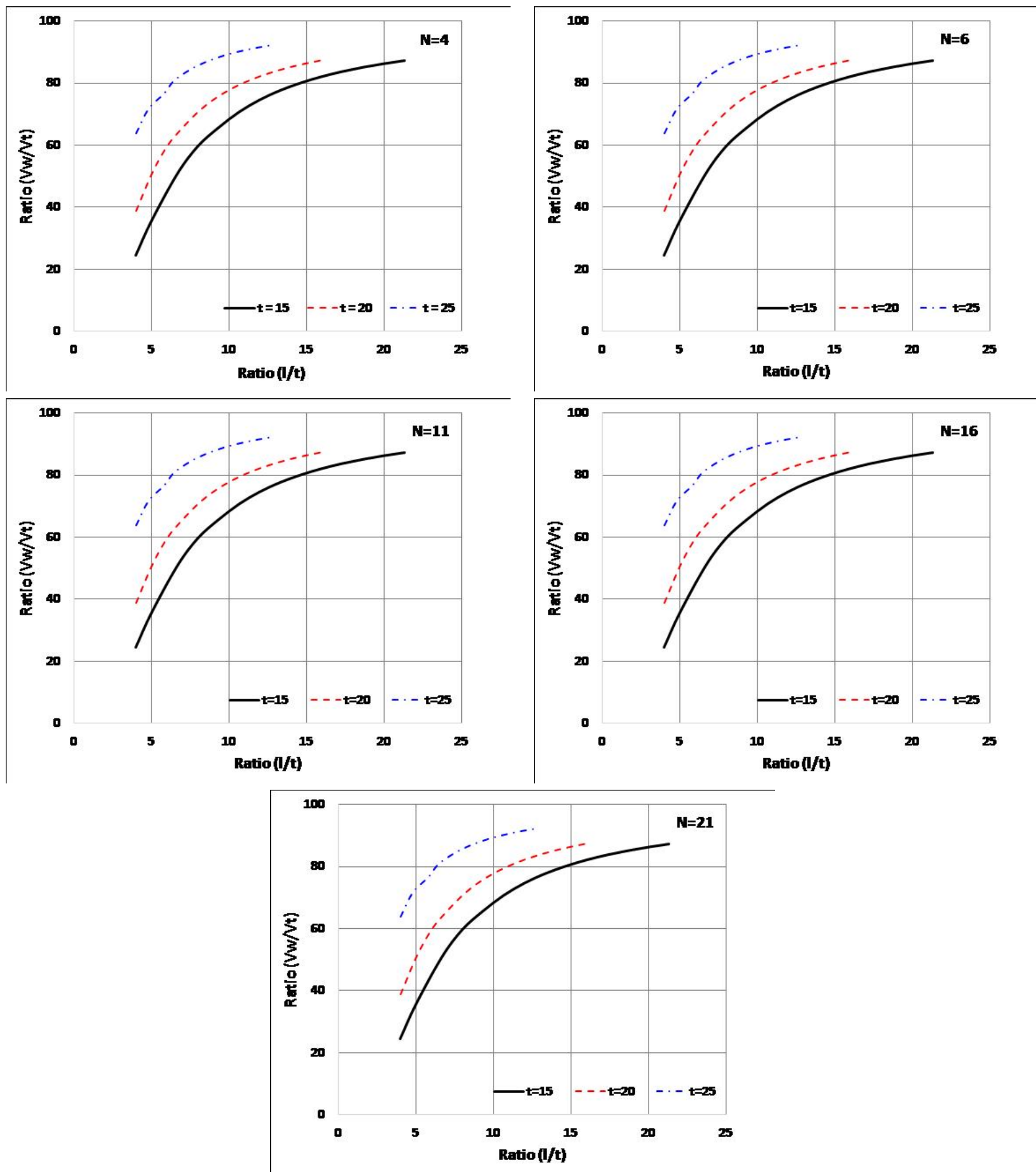

Fig. 6. Variation of the shear force ratios carried by walls to the total earthquake force for different wall thicknesses 

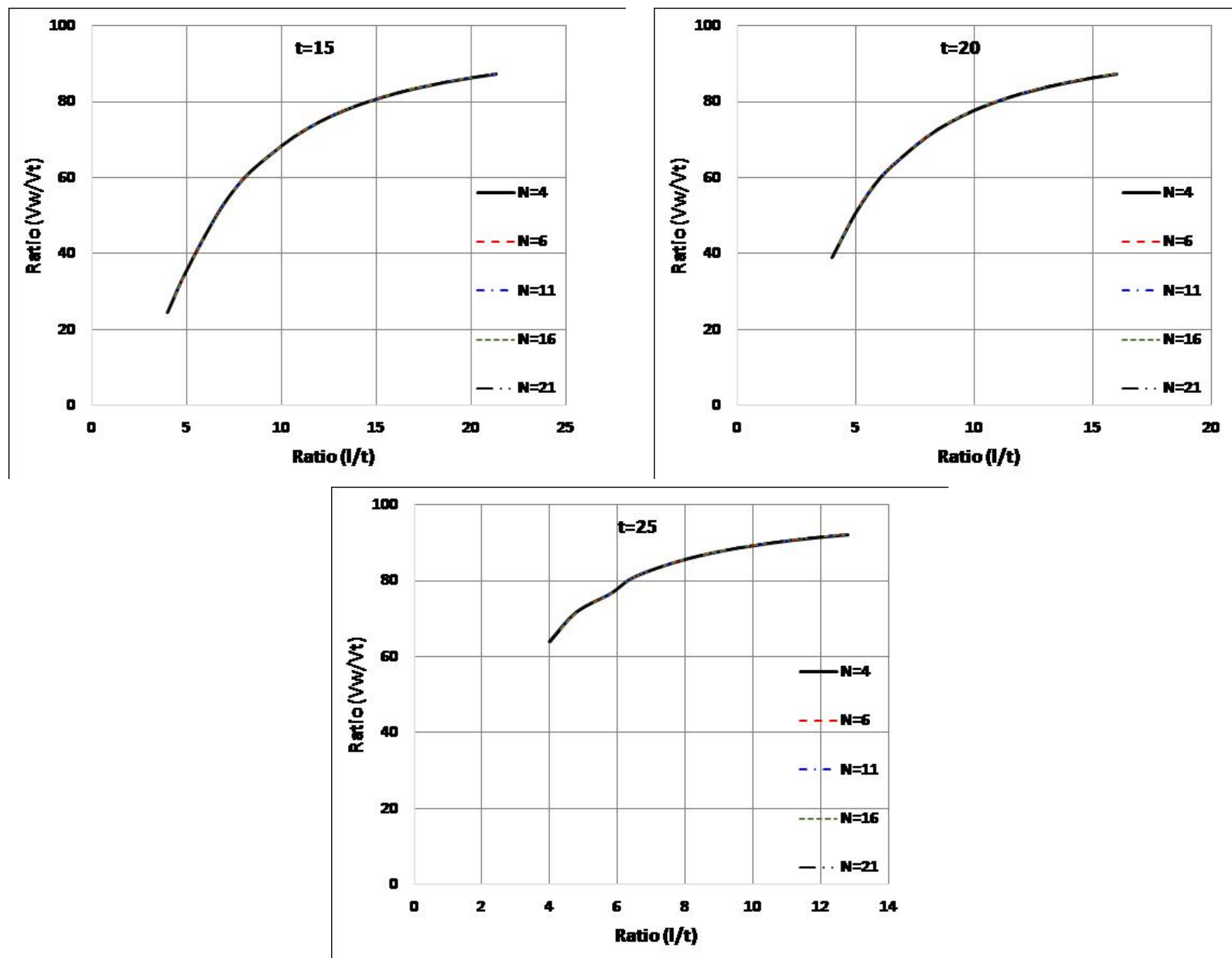

Fig. 7. Effect of number of stories $(N)$ on shear force ratios variation $(\mathrm{Vw} / \mathrm{Vt})$ for a given wall thickness

respectively 4 and 7 for buildings with walls of $20 \mathrm{~cm}$.

It was also found that, when the thickness of the walls increases the value of the peak stress shift toward lower values of the ratio $(t / l)$. The values of the maximum shear stress, that took place at different $l / t$ ratios, were the same for buildings of 4 and 6 stories regardless the thickness of the walls. However, for tall buildings, a difference in shear stress was observed especially for buildings having 16 and 21 stories.

Based on the investigation, it was recommended for $\mathrm{RC}$ shear walls of $15 \mathrm{~cm}$ thickness to have a length greater than 10 times the thickness, $1>10 \mathrm{t}$. For walls with 20 and $25 \mathrm{~cm}$ thickness this value is, respectively, 7 and 5 .

The amount of enhancement of the $(\mathrm{Vw} / \mathrm{Vt})$ ratio is important while passing from a wall thickness of 15 to $25 \mathrm{~cm}$ than a wall thickness of 15 to $20 \mathrm{~cm}$, especially for small $(l / t)$ ratios. For a small ratio of $L / t=4$, the enhancement $(\mathrm{Vw} / \mathrm{Vt})$ ratio passes from 1.59 to 2.61 , while increasing the wall s thicknesses from 15 to $20 \mathrm{~cm}$ and from 15 to $25 \mathrm{~cm}$, respectively. These values were only 1.10 and 1.22 for a larger ratio of $L / t=12$. The investigation showed also that the $(\mathrm{Vw} / \mathrm{Vt})-(l / t)$ relationships is the same for a given walls thickness, regardless the number of stories, $N$.

The authors suggest that, for a thorough understanding of the seismic behavior of reinforced concrete shear walls with an L shaped section, more analyzes and experimental testing should be carried out in the future.

\section{References}

1 Ousalem H, Bechtoula $\mathbf{H}$, Report on the damage investigation and postseismic campaign of 2003 Zemmouri earthquake in Algeria, The ERI the university of Tokyo; Ohbunsha press Japan, 2003.

2 Sakashita M, Bechtoula H, Kono S, Tanaka H, Watanabe F, A study on the seismic force resisting mechanism of a multi-story shear wall system considering the interaction between wall, slab, foundation beam, and pile elements, the 13 world conference on earthquake engineering 13 WCEE, In:; Vancouver, BC, Canada, 2004, p. paper ID 3482. papers published on CD.

3 Bechtoula H, Ousalem H, The 21 May Zemmouri, Algeria, Earthquake: Damage and disaster Response, The Journal of Advanced Concrete Technology, ACT, 3(1), (2005), 161-174.

4 Ousalem H, Bechtoula H, Inventory Survey of the 2003 Zemmouri, Algeria, Earthquake: Case Study of Dergana city, The Journal of Advanced Concrete Technology, ACT, 3, (2005), 175-183.

5 Taleb R, Bechtoula H, Sakashita M, Bourahla N, Kono S, Investigation of the shear Behaviour of multi-Story Reinforced Concrete walls with 
eccentric openings, Journal of Computer and Concrete, CAC, 10(4), (2012), 343-359.

6 Blakely R, Cooney RC, Megget LM, Seismic shear loading at flexural capacity in cantilever wall structures, Bulletin of the New Zealand National Society for Earthquake Engineering, 8(4), (1975), 278-290.

7 Lefas ID, Kotsovos MD, Ambraseys NN, Behavior of reinforced concrete structural walls: strength, deformation characteristics, and failure mechanism, ACI structural journal, 87(1), (1990), 23-31.

8 Sharon SL, Shear strength of low-rise reinforced concrete walls, ACI structural journal, 87(1), (1990), 99-107.

9 Lefas ID, Kotsovos MD, Ambraseys NN, Strength and deformation characteristics of reinforced concrete walls under load reversals, ACI structural journal, 87(6), (1990), 716-726.

10 Ebehart MO, Sozen MA, Behavior-based method to determine design shear in earthquake-resistant walls, Journal of Structural Engineering, 119(2), (1993).

11 Pilakoutas K, Elnashai A, Cyclic behavior of reinforced concrete cantilever walls, Part I: experimental results, ACI structural journal, 92(4), (1995), 271-281.

12 Thomson JH, Wallace JW, Displacement-based design of reinforced concrete structural walls: experimental studies of walls with rectangular and $t$ shaped cross sections, Department of Civil and environmental Engineering, Clarkson University; Potsdam NY, 1995. Report No CU/CEE-95/06.

13 Sittipunt C, Wood SL, Influence of web reinforcement on cyclic response of structural walls, ACI structural journal, 92(6), (1995), 745-756.

14 Zhang Y, Wang Z, Seismic behavior of reinforced concrete shear walls subjected to high axial loading, ACI structural journal, 97(5), (2000), 739-750.

15 Riva P, Franchi A, Behavior of reinforced concrete walls with welded wire mesh subjected to cyclic loading, ACI structural journal, 98(3), (2001), 324334.

16 Palermo D, Vecchio FJ, Behavior of three-dimensional reinforced concrete shear walls, ACI structural journal, 99(1), (2002), 81-89.

17 Adebar P, Ibrahim AMM, Simple non-linear flexural stiffness model for concrete shear walls, Earthquake Spectra EERI, 18(3), (2002), 407-426.

18 Hassen M, El-Tawil S, Tension flange effect width in reinforced concrete shear walls, ACI structural journal, 100(3), (2003), 349-356.

19 Watkins TW, Seismic demand in high-rise concrete walls, Phd Thesis, The University British Columbia, 2004.

20 Xuân Huy Nguyen, Vulnérabilité des structures en béton armé à voiles porteurs : Expérimentation et modélisation, Doctorat Thesis, INP Grenoble, 2006.

21 Maffei J, Yuen N, Seismic performance and design Requirements for HighRise Building, Structure Magazine, (2007), 28-32.

22 Inada K, Bechtoula H, Chosa H, Kono S, Watanabe F, Seismic performance of RC L-Shaped core structural walls, the 14th world conference on earthquake engineering, In:; Beijing, China, 2008, pp. paper 12-01-0134. papers published on $\mathrm{CD}$.

23 Karamlou A, Zaman Kabir M, Experimental study of L-Shaped slender $R$-ICF shear walls under cyclic lateral loading, Engineering structures, 36, (2012), 134-146.

24 Autodesk Robot Structural Analysis Professional, Autodesk; USA, 2011. 